\title{
Reelin expression in brain endothelial cells: an electron microscopy study
}

\author{
Emma Perez-Costas ${ }^{1}$, Erin Y Fenton ${ }^{2}$ and Hector J Caruncho ${ }^{2^{*}}$
}

\begin{abstract}
Background: Reelin expression and function have been extensively studied in the brain, although its expression has been also reported in other tissues including blood. This raises the possibility that reelin might be able to cross the blood-brain barrier, which could be functionally relevant. Up-to-date no studies have been conducted to assess if reelin is present in the blood-brain barrier, which is mainly constituted by tightly packed endothelial cells. In this report we assessed the expression of reelin in brain capillaries using immunocytochemistry and electron microscopy.

Results: At the light microscope, reelin immunolabeling appeared in specific endothelial cells in brain areas that presented abundant diffuse labeling for this protein (e.g., layer I of the cortex, or the stratum lacunosum moleculare of the hippocampus), while it was mostly absent from capillaries in other brain areas (e.g., deeper cortical layers, or the CA1 layer of the hippocampus). As expected, at the electron microscope reelin labeling was observed in neurons of the cortex, where most of the labeling was associated with the rough endoplasmic reticulum. Importantly, reelin was also observed in some endothelial cells located in small capillaries, which confirmed the findings obtained at the light microscope. In these cells, reelin labeling was located primarily in caveolae (i.e., vesicles of transcytosis), and associated with the plasma membrane of the luminal side of endothelial cells. In addition, some scarce labeling was observed in the nuclear membrane.

Conclusions: The presence of reelin immunolabeling in brain endothelial cells, and particularly in caveolar vesicles within these cells, suggests that reelin and/or reelin peptides may be able to cross the blood-brain barrier, which could have important physiological, pathological, and therapeutic implications.
\end{abstract}

Keywords: Blood-brain-barrier, Transcytosis, Brain capillaries

\section{Background}

Reelin is a large extracellular matrix glycoprotein, which was originally discovered in the mouse brain [1]. This protein is secreted by Cajal-Retzius cells during brain development, regulating neural migration and dendritic spine maturation (see as reviews [2-5]). In the adult brain, reelin is expressed primarily in cortical and hippocampal GABAergic neurons as well as in cerebellar granule cells [6-10]. In the mature brain, it is involved in a variety of functions, including the ccontrol of neurotransmitter release [11,12], maturation and stabilization of dendritic spines [13-15], specification of the molecular

\footnotetext{
* Correspondence: hector.caruncho@usask.ca

${ }^{2}$ Division of Pharmacy, College of Pharmacy and Nutrition, University of Saskatchewan, 1B23 Health Sciences Building, 107 Wiggins Road, Saskatoon, SK S7N 5E5, Canada

Full list of author information is available at the end of the article
}

identity of the distal dendritic compartment of pyramidal neurons [16], regulation of glutamate receptor homeostasis [17], and in the regulation of different aspects of adult hippocampal neurogenesis [18-25]. However, reelin expression is not restricted to the central nervous system (CNS), and has also been observed in the enteric nervous system [26], blood serum, liver, pituitary pars intermedia, and adrenal chromaffin cells [27], as well as in platelets [28], and lymphatic vessels $[29,30]$. The functional roles of reelin outside the CNS have been less studied, although it has been suggested that reelin enhances spreading of platelets on fibrinogen [28], and participates in the regulation of lymphatic vessel formation [30].

Some ultrastructural studies have focused primarily on the subcellular expression of reelin in neurons and neuropil within the CNS, where immunolabeling has been reported in the rough endoplasmic reticulum, axons, 
dendritic spines, and in the extracellular matrix [31-35]. However, as far as we know there are no reports on the possible expression of reelin in the main component of the blood-brain barrier, the brain endothelial cells. The expression of reelin in this particular type of endothelial cells, and in specific subcellular compartments within them, could be related to possible roles for this protein in the regulation of brain microvasculature (i.e., as it has been shown for lymphatic vessels), and/or mediating an interconnection between brain and peripheral tissues (i.e., being transported by transcytosis). In order to assess these possibilities we undertook an electron microscopy study of reelin immunolabeling in brain endothelial cells.

\section{Results and discussion}

In this study we focused on reelin immunolabeling in the adult rat cortex and hippocampus. As shown in previous studies [6-9,13,34,35], at the light microscope the most intense reelin labeling was observed in layer I of the cortex and in the stratum lacunosum moleculare of the hippocampus, where neuronal and diffuse labeling were observed (Figure 1). Interestingly, at higher magnification reelin labeling also appeared in some (but not all) capillaries within areas containing strong diffuse immunolabeling, such as layer I of the cortex (Figures 1A-B) and the stratum lacunosum moleculare of the hippocampus (Figures 1E-F). On the other hand, reelin-labeled capillaries were not observed in areas lacking diffuse immunostaining, such as deeper layers of the cortex, and the CA1 area of the hippocampus (Figures 1C-D, G-H). The fact that reelin immunostaining was only observed in some (but not all) capillaries within areas presenting strong diffuse labeling argues in favor of its specificity. In addition, this also suggests that a possible secretion and/or transport of reelin by endothelial cells may take place primarily in areas of heavy diffuse reelin staining (i.e., brain areas where reelin tends to accumulate in the extracellular matrix) [see reference 32].

Our electron microscopy study confirmed and extended our findings. As expected, reelin immunostaining was found in neurons, where labeling was located in discrete regions of the rough endoplasmic reticulum (Figures 2A-C), which is in agreement with previous studies [31-35], and is also consistent with the fact that reelin is an extracellular matrix protein expressed through the secretory pathway. Importantly, we have also confirmed that some endothelial cells associated with small capillaries contain reelin immunostaining (Figure 3), while others appear devoid of labeling (Figure 4). High magnification electron micrographs allowed us the identification of the subcellular distribution of reelin labeling, which was mostly located inside vesicles of transcytosis (Figures 3B-C, E-F). In fact, we were able to observe almost all stages of the transcytosis vesicles, from the formation of one of these vesicles accumulating reelin immunostaining (Figure 3B), to reelin-labeled caveolar vesicles located close to the lumen of the capillary or even showing the opening neck (Figures 3C, E-F). In addition, reelin labeling was also found in the endothelial plasma membrane bordering the capillary lumen (Figures 3E-F), but not in the abluminal side (Figures 3B-C, E-F). Furthermore, we found some punctual labeling in the nuclear envelope, which may suggest a possible synthesis of reelin by endothelial cells; although we did not observe immunolabeling in the Golgi complex of these cells, which is poorly developed. Finally, we also found capillaries completely devoid of reelin labeling (Figure 4) in the same electron microscopy sample of the cortex, confirming our light microscopy observation that reelin appears in some (but not all) capillaries within the same area.

Although out of the scope of the present work, the presence of reelin immunolabeling in brain endothelial cells suggests that this protein may play a role in regulating the formation of brain microvasculature through a mechanism similar to the previously reported for lymphatic vessels [30]. Interestingly, it has been previously reported that in the cerebral cortex there are differences in the orientation of the cerebral vasculature between reeler and wild type mice, which suggests that reelin may be involved in blood vessel development [36]. However, additional experiments will be necessary to test whether reelin plays a role in the formation of brain microvasculature.

The fact that reelin labeling was observed in caveolar vesicles in different stages (i.e., from vesicles just formed close to the abluminal side of the plasma membrane, to others developing an open neck to the capillary lumen) indicates a possible process of transcytosis, which suggests that reelin may cross the blood-brain barrier. Alternatively, reelin transport might be also from the brain parenchima to the periphery, or may occur in both directions. Interestingly, it has been shown that apolipoprotein-E receptor-2 (ApoER2), which together with the very-lowdensity-lipoprotein receptor (VLDLR) constitutes the receptor for reelin, tends to co-immunoprecipitate with caveolin 1, and to localize in caveolae [37,38]. Taking together our findings and these previous reports, it is possible that the crossing of the blood-brain barrier might be accomplished via a receptor-mediated mechanism that includes ApoER2. In addition, it has been shown that the adaptor protein DAB1 also tends to cluster within specific membrane domains (i.e., in detergent-resistant membrane fractions such as lipid rafts and caveolar vesicles) $[39,40]$, that reelin induces the clustering of its own receptor Apolipoprotein ER2 and other proteins [41,42], and that the sorting of these proteins to different membrane domains yields differential endocytosis of reelin [43]. We have recently shown that deficits in reelin expression result in changes in membrane protein clustering 


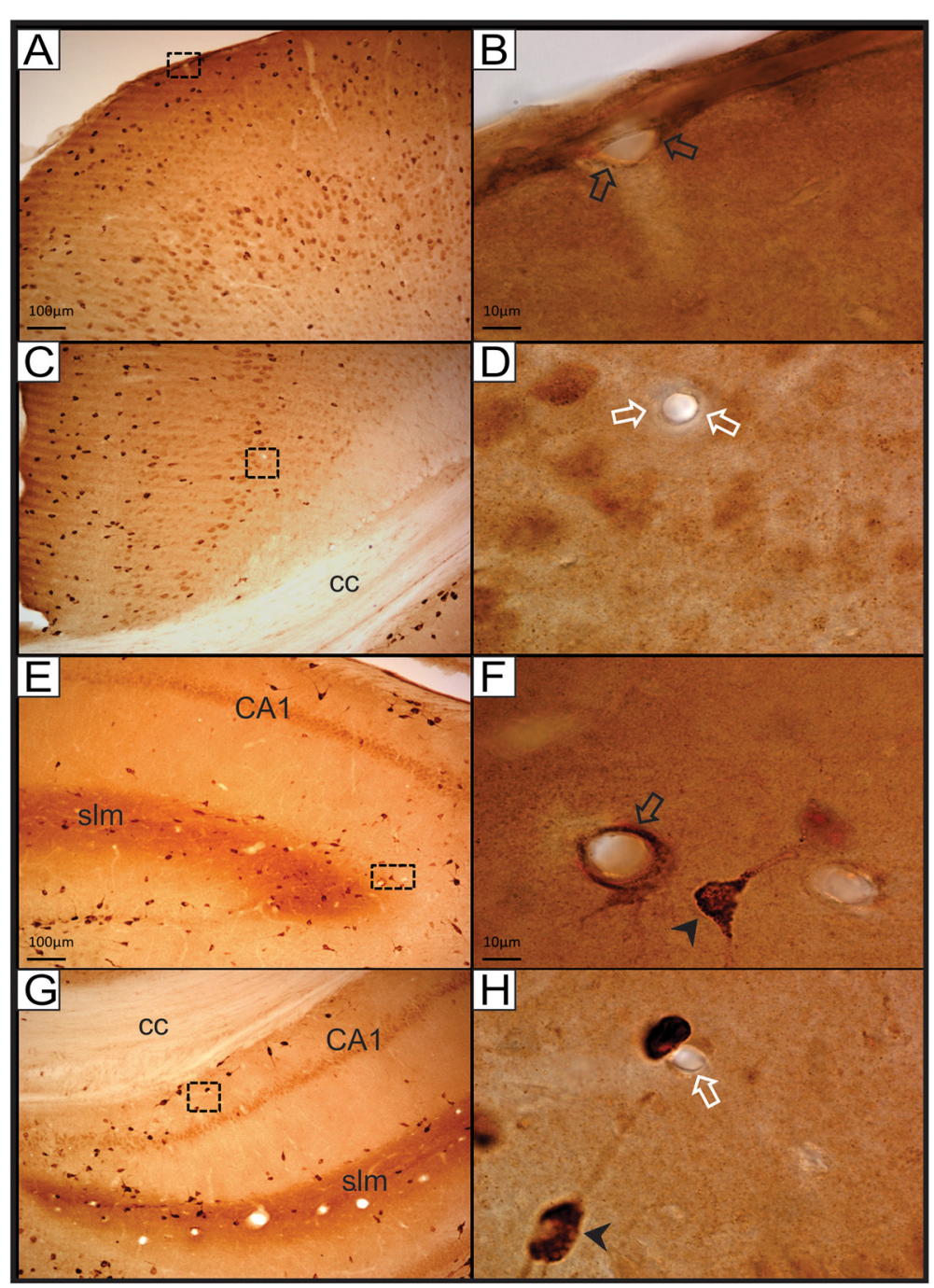

Figure 1 Reelin labeling at the light microscope. A) Reelin immunolabeling in superficial and mid-layers of the cortex. As expected, reelin-labeled neurons are present across different layers of the cortex, and diffuse labeling is mostly present in the superficial layers. B) High magnification of the area indicated with a dashed-line box in A. This image shows a reelin-immunolabeled blood capillary in layer I of the cortex (empty black arrows). C) Reelin labeling in deeper layers of the cortex. Scattered reelin-labeled neurons in these deeper layers present moderate labeling compared to superficial layers. D) High magnification image of the area indicated with a box in C. The capillary is negative for reelin labeling (empty white arrows). E) Reelin labeling in the lateral part of the rostral hippocampus. Note the row of lightly reelin-labeled neurons in the CA1, as well as the diffuse reelin immunolabeling in the stratum lacunosum moleculare (s/m). F) High magnification image of an area neighboring the slm, corresponding to the dashed-line area indicated in E. Note the intense reelin labeling surrounding this capillary (empty black arrow). In addition there is a strongly labeled neuron in close proximity (black arrowhead). G) Reelin labeling in the medial part of the rostral hippocampus. The corpus callosum (cc) appears dorsally bordering the hippocampus. H) High magnification image of the dashed-line box area in G. Note the unlabeled capillary (empty white arrow) located in close proximity to a strongly labeled neuron (black arrowhead). cc: corpus callosum; CA1: Cornu Ammonis layer l; slm: stratum lacunosum moleculare. Scale bars: 10 microns in A, C, G, E; 100 microns in B, D, F, H

in peripheral lymphocytes [44], and that the addition of recombinant reelin to synaptosomes increase protein expression and alters membrane protein clustering $[45,46]$. Interestingly, there is a decrease in reelin expression in the brain and periphery of patients diagnosed with depression $[47,48]$, and we have found alterations in membrane protein clustering in lymphocytes from patients with depression, which correlated with therapeutic response to antidepressants $[49,50]$. All these evidence point towards an important role for reelin in membrane protein clustering in both brain and periphery. The presence of reelin in caveolar vesicles of brain endothelial cells suggests a possible role for this protein in the regulation of the crosstalk between brain and immune system, and in the perturbation of this crosstalk in several psychiatric disorders. Although the specific consequences of reelin 


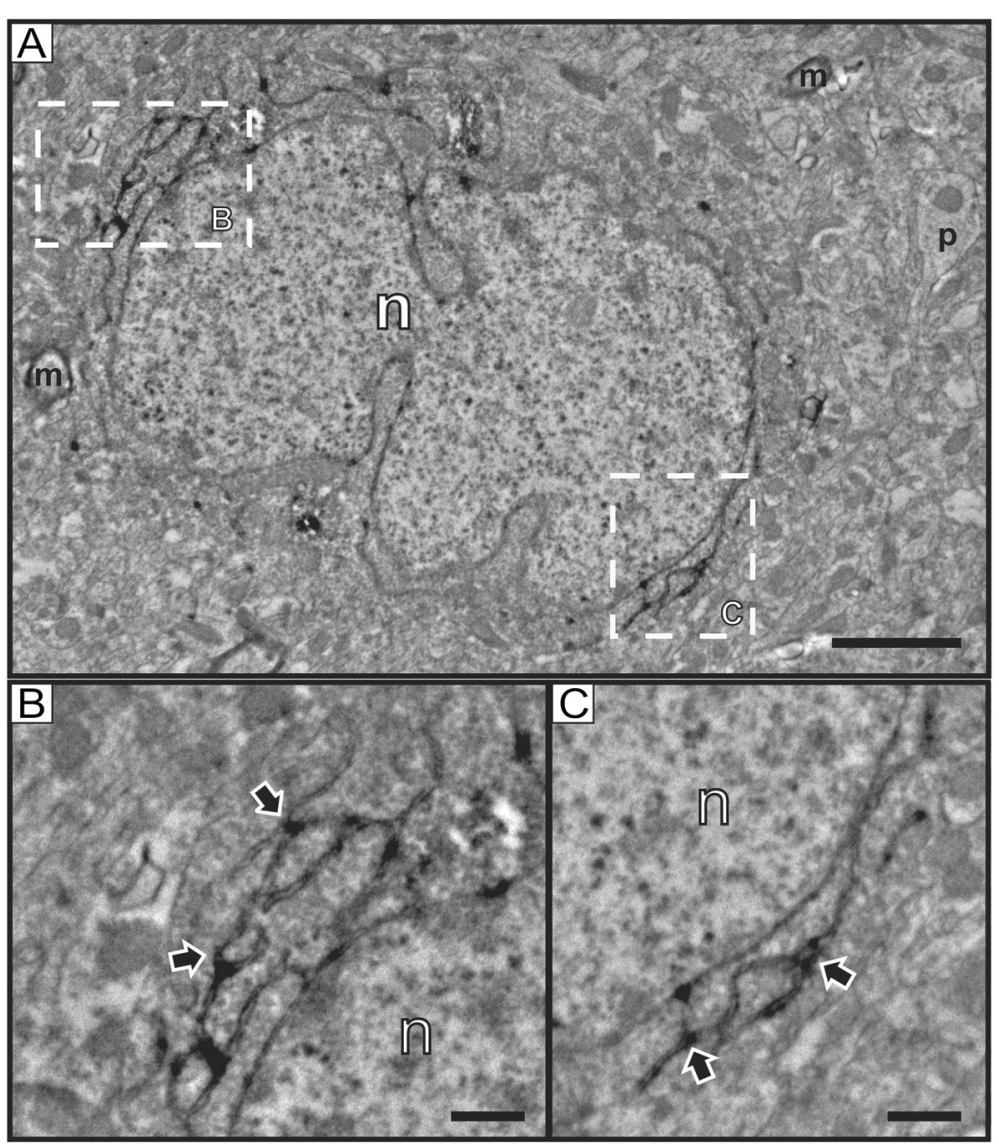

Figure 2 Reelin neuronal labeling at the electron microscope. A) Low magnification electron microscopy image of a reelin immunolabeled neuron in the cortex. B-C) Detail images of the areas indicated with dashed-line boxes in A. Note that reelin labeling is specifically located in the rough endoplasmic reticulum (outlined black arrows). $\mathbf{m}$ : myelinated process; $\mathbf{n}$ : nucleus; $\mathbf{p}$ : neuronal process. Scale bars: 2 microns in A; 0.5 microns in $\mathbf{B}-\mathbf{C}$.

downregulation in psychiatric disorders are still unknown, and it should be also taken into account that reelin deficits could be associated with brain cell malfunction independent of its association with the blood-brain barrier.

It does not escape to us that if reelin was able to cross the blood-brain barrier, it would be easier to design reelin peptides as possible therapeutic agents for psychiatric disorders. This is of particular interest taking into account that overexpression of reelin has been shown to prevent behavioral phenotypes in animal models of mood and psychotic disorders [51].

\section{Conclusions}

Reelin immunolabeling is specifically present in caveolar vesicles within endothelial cells located in brain areas that present strong reelin labeling in the extracellular matrix. In addition, electron microscopy images evidence that reelin-labeled caveolar vesicles can be observed from their formation to the opening of their membrane towards the capillary lumen. Altogether, these observations suggest that reelin and/or reelin peptides might cross the bloodbrain barrier, which could have important physiological, pathological, and therapeutic implications.

\section{Methods}

\section{Tissue preparation}

Rat brain samples were obtained from adult male rats (Charles River, Montreal, Canada) weighting between 225 and 250 grams at arrival to the animal facility. Animals were kept in a $12 / 12$ hour night/day cycle with water and food ad libitum until endpoint. The rat brain tissue used in this study belonged to a stock of spare samples prepared for light and electron microscopy. Procedures for tissue collection were approved by the University of Saskatchewan Committee on Animal Care and Supply, in strict accordance with the Canadian Council on Animal Care Guidelines. The protocols used in this study were also in accordance with the Institutional Animal Care and Use Committee (IACUC) guidelines at the University of Alabama at Birmingham, and the National Institutes of Health guidelines for the care and use of 


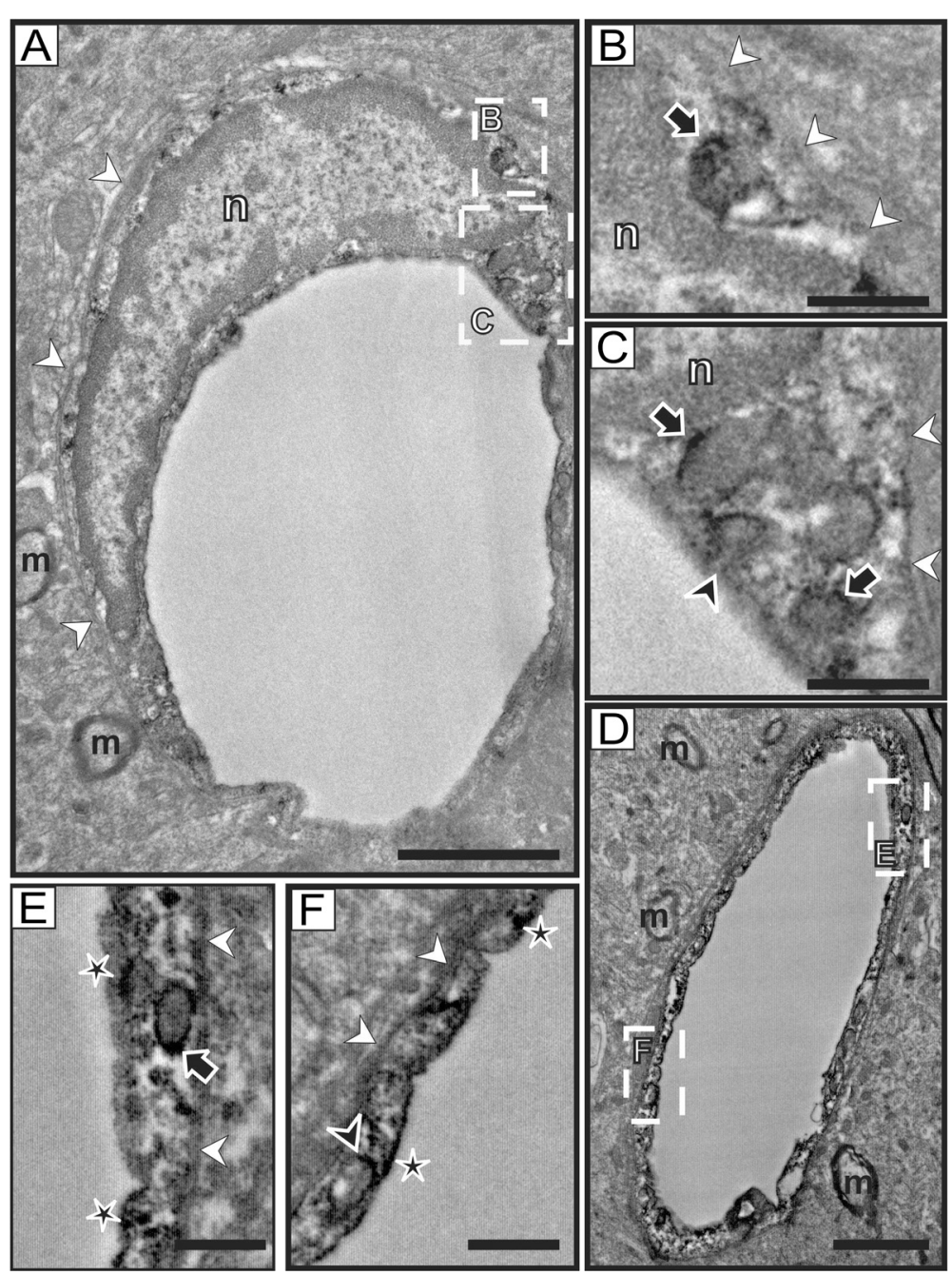

Figure 3 Reelin labeling in endothelial cells. A) Low magnification electron microscopy image of a reelin-labeled endothelial cell in the cortex This endothelial cell presents a thin cytoplasm, which is clearly delimited by the basement membrane (white arrowheads) in the abluminal side. The nucleus (n) occupies most of the cell body of the endothelial cell. B-C) Details of the areas marked with dashed-lined boxes in A. In B, a reelin-labeled transcytosis vesicle (outlined black arrow) is located in a narrow cytoplasm area between the nucleus ( $\mathrm{n}$ ) and the cell membrane (white arrowheads). In C, a small cluster of reelin-labeled caveolar vesicles is shown (outlined black arrows), with one of them presenting the open neck towards the capillary lumen (outlined black arrowhead). Note also that the abluminal side (white arrowheads) is devoid of labeling. D) Reelin labeling in a small brain capillary in the cortex. This capillary is formed by the almost-continuous thin cytoplasm of a reelin-labeled endothelial cell. Note also the lack of labeling in myelinated processes $(\mathrm{m})$ located in the vicinity of this capillary. E-F) Detail images of the areas indicated by dashed-line boxes in D. Reelin-labeled caveolar vesicles are present in different stages. A labeled caveolar vesicle in E (outlined black arrow) presents a well-delineated oval shape, while a labeled caveolar vesicle in $\mathrm{F}$ that is located in close proximity to the luminal side of the capillary is about to form the open neck (outlined black arrowhead). Note also the presence of reelin labeling in the luminal side of the membrane (outlined black stars), and the lack of labeling in the abluminal side (white arrowheads). $\mathbf{m}$ : myelinated process; $\mathbf{n}$ : nucleus. Scale bars: 2 microns in $\mathbf{A}, \mathbf{D} ; 0.5$ microns in $\mathbf{B}-\mathbf{C}$ and $\mathbf{E}-\mathbf{F}$.

animals in experimental procedures (USA). Rats were deeply anesthetized with sodium pentobarbital and transcardially perfused with saline solution $(0.9 \% \mathrm{NaCl})$, followed by $4 \%$ paraformaldehyde in $0.1 \mathrm{M}$ phosphate buffer (PB), pH 7.4. Brains were post-fixed in $4 \%$ paraformaldehyde for $72 \mathrm{hr}$ at $4^{\circ} \mathrm{C}$, thoroughly rinsed in $\mathrm{PB}$ and stored in PB containing $0.02 \%$ sodium azide. Brain sections (50 micron thick) were obtained in the coronal plane on a vibrating microtome. Sections at the level of the rostral hippocampus were used for light and electron microscopy.

\section{Light Microscopy immunohistochemistry}

Free-floating sections were thoroughly rinsed in $0.01 \mathrm{M}$ phosphate buffered saline (PBS) $\mathrm{pH} 7.4$, and subsequently treated with $0.3 \%(\mathrm{v} / \mathrm{v}) \mathrm{H}_{2} \mathrm{O}_{2}$ in PBS for $30 \mathrm{~min}$ to block endogenous peroxidase activity. They were then pre-incubated for $30 \mathrm{~min}$ in a blocking solution 


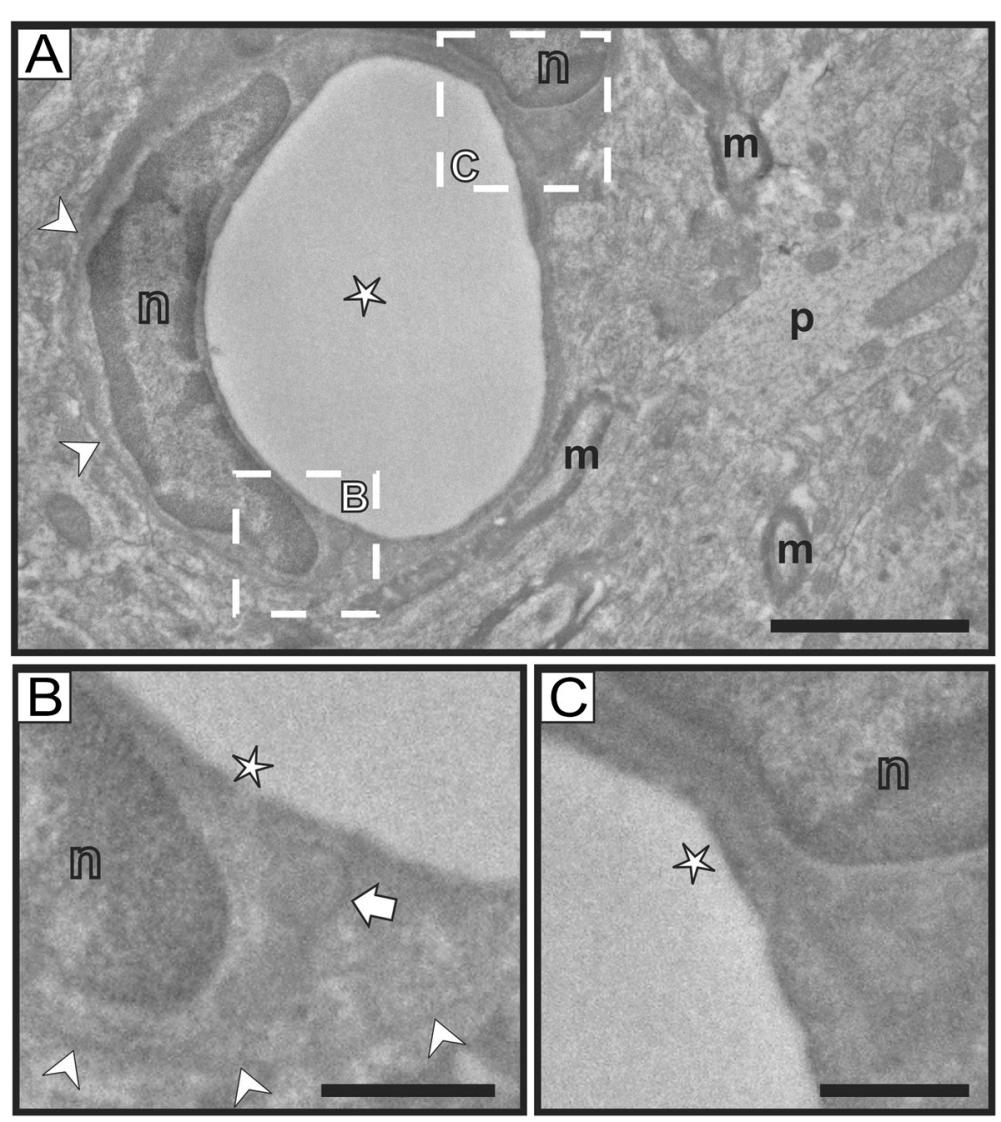

Figure 4 Reelin labeling is not present in all endothelial cells. A) Low magnification image of an unlabeled brain capillary in the cortex. The wall of this brain capillary is lined by at least two endothelial cells, as shown by the presence of their nuclei (n). Note also the presence of unlabeled myelinated $(\mathrm{m})$ and non-myelinated $(\mathrm{p})$ neuronal processes. The basement membrane was also clearly present (white arrowheads). B-C) Detail images of areas indicated with dashed-lined boxes in A. In B, a caveolar vesicle is clearly unlabeled (white arrow). In B and C, the luminal side of the endothelial cell membrane is also devoid of labeling (white stars). $\mathbf{m}$ : myelinated process; $\mathbf{n}$ : nucleus; $\mathbf{p}$ : neuronal process. White arrowheads indicate the membrane in the abluminal side Scale bars: 2 microns in $\mathbf{A} ; 0.5$ microns in $\mathbf{B}-\mathbf{C}$.

containing $0.3 \%$ Triton X-100, 5\% normal horse serum (NHS; Vector Laboratories, Burlingame, CA, USA), and $1 \%$ bovine serum albumin (BSA) dissolved in PBS in order to block any non-specific antibody binding. The sections were then incubated with a mouse monoclonal anti-reelin antibody (Millipore clone G-10 Cat\# MAB5364, RRID: AB_2179313; diluted 1:2000, $48 \mathrm{hr}$, at $4^{\circ} \mathrm{C}$ ). This incubation was followed by three rinses in PBS and incubation for 1 hour at room temperature with a biotinylated horse anti-mouse secondary antibody (Vector Laboratories) diluted 1:200 in PBS containing 0.3\% (v/v) Triton X-100. After several rinses in PBS, the sections were incubated with a peroxidase-coupled avidin-biotin complex (VectaStain Elite ABC Kit, Vector Laboratories) for 90 minutes at room temperature. To visualize the immunolabeling, the sections were developed using a solution of $0.033 \%$ 3,3'diaminobenzidine (DAB) and $0.00786 \% \mathrm{H}_{2} \mathrm{O}_{2}$ prepared in PBS. The reaction was stopped using PBS as a rinse. The sections were then mounted onto slides, allowed to dry overnight, dehydrated in ethanol, cleared in xylene and coverslipped using Entellan resin (Millipore, USA). Omission of the primary antibody resulted in a complete lack of immunostaining (not shown). In addition, labeling with a different anti-reelin primary antibody (Reln $A B 142$ ) yielded similar results than those obtaining using the G-10 anti-reelin antibody (data not shown).

Light microscopy images of reelin immunolabeling were obtained using a computerized Nikon E800 microscope.

\section{Electron Microscopy immunohistochemistry}

Free-floating sections were treated with $1 \%$ sodium borohydride in PBS for 15 minutes and thoroughly rinsed in PBS (5 rinses, $5 \mathrm{~min}$ each). Endogenous peroxidase was blocked by immersing the sections in a solution of $5 \%$ hydrogen peroxide in PBS for 30 minutes, which was followed by 5 rinses ( 5 min each) in PBS. Afterwards, to block non-specific binding sites in the sections, a blocking solution of $10 \%$ NHS prepared in PBS containing $0.1 \%$ Triton X-100 was applied for one hour. The sections were then incubated for 72 hours at $4^{\circ} \mathrm{C}$ with a 
mouse monoclonal anti-reelin antibody (Millipore clone G-10 Cat\# MAB5364, RRID:AB_2179313clone) diluted 1:1000 in PBS containing 5\% NHS. After 5 rinses (5 min each) in PBS, the sections were incubated with a biotinylated horse anti-mouse secondary antibody (Vector Laboratories) diluted 1:400 for 45 minutes at room temperature, and rinsed in PBS (5 times, 5 min each). Finally, the sections were incubated for 45 minutes with a peroxidase-coupled avidin-biotin complex (Vecta-Stain Elite ABC Kit, Vector Laboratories), rinsed in PBS, and the reaction was developed using a 3-3' diaminobenzidine-peroxidase kit (DABperoxidase kit, Vector Laboratories). The reaction was stopped by rinsing the sections in PBS, and the sections were further rinsed in $\mathrm{PB}$ prior to embedding for electron microscopy. After immunocytochemistry, all sections for electron microscopy were postfixed overnight at $4{ }^{\circ} \mathrm{C}$ in $2 \%$ glutaraldehyde prepared in PB.

Sections were embedded for electron microscopy as previously described in Perez-Costas et al [52], with some modifications. After several rinses in PB, immunolabeled sections were immersed in a solution of $1 \%$ osmium tetroxide in $\mathrm{PB}$ for 1 hour at room temperature, rinsed in $\mathrm{PB}$ two times (5 min each), and gradually dehydrated in a series of ethanol $(30 \%, 50 \%, 70 \% \mathrm{v} / \mathrm{v}$ of ethanol in milli-Q ultrapure water). After this partial dehydration, sections were stained with a solution of $1 \%$ uranyl acetate in $70 \%$ ethanol for 1 hour at room temperature, and then dehydration was completed by immersing the sections gradually in $90 \%$ and $100 \%$ ethanol (3 baths, 5 min each). After dehydration the sections were cleared in propylene oxide ( 2 baths, 5 min each), progressively infiltrated at room temperature with Epon resin diluted in propylene oxide (1:1 v/v propylene oxide/resin, 30 minutes; followed by v/v 1:2 propylene oxide/resin, 1 hour). Finally, the sections were immersed in pure Epon resin overnight at $4^{\circ} \mathrm{C}$, transferred to freshly-prepared Epon resin for flatembedding, and allowed to polymerize in an oven set at $60^{\circ} \mathrm{C}$ for 72 hours. In order to select the regions of interest (i.e. frontal cortex), the embedded sections were visualized on a Nikon Eclipse 50 I light microscope, carefully identifying the cortical region of interest, and re-dissecting this region for ultramicrotomy. Ultrathin sections $(90 \mathrm{~nm}$ thick) were obtained using a Leica UC6 ultramicrotome (Leica Microsystems, Wetzlar, Germany) and mounted on copper-slot grids (Electron Microscopy Sciences, USA). Immunolabeled cortex samples were then observed and photographed using a transmission electron microscope (H-7650, Hitachi, Japan) equipped with a Hamamatsu Orca HR digital camera (Hamamatsu, Japan).

\section{Photomontage and lettering}

Adjustment of brightness/contrast and figure plate lettering were done using Corel Draw X5 (Corel Corporation, Ottawa, Canada)

\section{Competing interests}

The authors declare that they have no competing interests.

\section{Authors' contributions}

EP-C performed the electron microscopy experiments and contributed to the design of the study; EYF performed the optical microscopy experiments and contributed to the design of the study; HJC conceived and designed the study, and evaluated the data. All authors contributed to drafting the manuscripts and have given final approval of the version to be published.

\section{Acknowledgments}

HJC was supported by start-up funds from the University of Saskatchewan, and an Establishment Grant from the Saskatchewan Health Research Foundation.

\section{Author details}

'Department of Psychology, University of Alabama at Birmingham, College of Arts and Sciences, Campbell Hall 415, 1720 2nd Avenue South, Birmingham, Alabama 35294, USA. ²Division of Pharmacy, College of Pharmacy and Nutrition, University of Saskatchewan, 1B23 Health Sciences Building, 107 Wiggins Road, Saskatoon, SK S7N 5E5, Canada.

Received: 4 November 2014 Accepted: 11 March 2015

Published online: 24 March 2015

\section{References}

1. D'Arcangelo G, Miao GG, Chen S-C, Soares HD, Morgan Jl, Curran T. A protein related to extracellular matrix proteins deleted in the mouse mutant reeler. Nature. 1995;374:719-23.

2. Tissir F, Goffinet AM. Reelin and brain development. Nat Rev Neurosci. 2003;4:496-595.

3. Forster $\mathrm{E}$, Bock HH, Herz J, Chai $X$, Frotscher M, Zhao S. Emerging topics in reelin function. Eur J Neurosci. 2010;31:1511-8.

4. Lakatosova S, Ostatnikova D. Reelin and its complex involvement in brain development and function. Int J Biochem \& Cell Biol. 2012;44:1501-4.

5. Stranahan AM, Erion JR, Wosiski-Kuhn M. Reelin signaling in development, maintenance, and plasticity of neuronal networks. Ageing Res Rev. 2013;12:815-22.

6. Alcantara S, Ruiz M, D'Arcangelo G, Ezan F, de Lecea L, Curran T, et al Regional and cellular patterns of reelin mRNA expression in the forebrain of the developing and adult mouse. J Neurosci. 1998;18:7779-99.

7. Pesold C, Impagnatiello F, Pisu MG, Uzunov DP, Costa E, Guidotti A, et al. Reelin is preferentially expressed in neurons synthesizing g-aminobutyric acid in cortex and hippocampus of adult rats. Proc Natl Acad Sci USA. 1998;95:3221-6.

8. Pesold C, Liu WS, Guidoti A, Costa E, Caruncho HJ. Cortical bitufted, horizontal, and Martinotti cells preferentially express and secrete reelin into perineuronal nets, nonsynaptically modulating gene expression. Proc Natl Acad Sci USA. 1999;96:3217-22.

9. Ramos-Moreno T, Galazo MJ, Porrero C, Martinez-Cerdeño V, Clasca F. Extracellular matrix molecules and synaptic plasticity: immunomapping of intracellular and secreted reelin in the adult rat brain. Eur J Neurosci. 2006;23:401-22.

10. Pohlkamp T, David C, Cauli B, Gallopin T, Bouche E, Karagiannis A, et al. Characterization and distribution of reelin-positive interneurons in the rat barrel cortex. Cereb Cortex. 2014;24:3046-58.

11. Hellwig S, Hack I, Kowalski J, Brunne B, Jarowyj J, Unger A, et al. Role for reelin in neurotransmitter release. J Neurosci. 2011;31:2352-60.

12. Bal M, Leitz J, Reese AL, Ramirez DMO, Durakoglugil M, Herz J, et al. Reelin mobilizes a VAMP-dependent synaptic vesicle pool and selectively augments spontaneous neurotransmission. Neuron. 2013;80:934-46.

13. Rodriguez MA, Pesold C, Liu WS, Kriho V, Guidotti A, Pappas GD, et al. Colocalization of integrin receptors and reelin in dendritic spine postsynaptic densities of adult non-human primate cortex. Proc Natl Acad Sci USA. 2000;97:3550-5.

14. Niu S, Yabut O, D'Arcangelo G. The reelin signaling pathway promotes dendritic spine development in hippocampal neurons. J Neurosci. 2008;28:10339-448.

15. Charneau $P$, Inta D, Vitalis T, Monyer H, Wadman WJ, van Hooft JA. The $\mathrm{N}$-terminal region of reelin regulates postnatal dendritic maturation of cortical pyramidal neurons. Proc Natl Acad Sci USA. 2009;106:7227-32. 
16. Kupferman JV, Basu J, Russo MJ, Guevarra J, Cheung SK, Siegelbaum SA. Reelin signaling specifies the molecular identity of the pyramidal neuron distal dendritic compartment. Cell. 2014;158:1335-47.

17. Gonzalez-Campo C, Sinagra M, Verrier D, Manzoni OJ, Chavis P. Reelin secreted by GABAergic neurons regulates glutamate receptor homeostasis. PLoS One. 2009;4:e5505.

18. Gong C, Wang TW, Huang HS, Parent JM. Reelin regulates neuronal progenitor migration in intact and epileptic hippocampus. J Neurosci. 2007;27:1803-11.

19. Zhao S, Chai X, Frotscher M. Balance between neurogenesis and gliogenesis in the adult hippocampus: role for reelin. Dev Neurosci. 2007;29:84-90.

20. Lussier AL, Caruncho HJ, Kalynchuk LE. Repeated exposure to corticosterone, but not restraint, decreases the humber of reelin-positive cells in the adult rat hippocampus. Neurosci Lett. 2009;460:170-4.

21. Lussier AL, Romay-Tallon R, Kalynchuk LE, Caruncho HJ. Reelin as a putative vulnerability factor for depression: Examining the depressogenic effects of repeated corticosterone in heterozygous reeler mice. Neuropharmacology. 2011:60:1064-74

22. Lussier AL, Lebedeva K, Fenton EY, Guskjolen A, Caruncho HJ, Kalynchuk LE. The progressive development of depression-like behavior in corticosterone-treated rats is paralleled by slowed granule cell maturation and decreased reelin expression in the adult dentate gyrus. Neuropharmacology. 2013;71:174-83.

23. Fournier NM, Andersen DR, Botterill JJ, Sterner EY, Lussier AL, Caruncho HJ, et al. The effect of amygdala kindling on hippocampal neurogenesis coincides with decreased reelin and DISC1 expression in the adult dentate gyrus. Hippocampus. 2010;20:659-71.

24. Pujadas L, Gruart A, Bosch C, Delgado L, Teixeira CM, Rossi D, et al. Reelin regulates postnatal neurogenesis and enhances spine hypertrophy and long-term potentiation. J Neurosci. 2010;30:4636-49.

25. Teixeira CM, Kron MM, Masachs N, Zhang H, Lagace DC, Martinez A, et al. Cell-autonomous inactivation of the reelin pathway impairs adult neurogenesis in the hippocampus. J Neurosci. 2012;32:12051-65.

26. Bottner M, Ghorbani P, Harde J, Barrenschee M, Hellwig I, Vogel I, et al. Expression and regulation of reelin and its receptors in the enteric nervous system. Mol Cell Neurosci. 2014;61:23-33.

27. Smalheiser NR, Costa E, Guidotti A, Impagnatiello F, Auta J, Lacor P, et al. Expression of reelin in adult mammalian blood, liver, pituitary pars intermedia, and adremal chromaffin cells. Proc Natl Acad Sci USA. 2000:97:1281-6.

28. Tseng W-L, Huand C-L, Chong K-Y, Liao C-H, Stern A, Cheng J-C, et al. Reelin is a platelet protein and functions as a positive regulator of platelet spreading on fibrinogen. Cell Mol Life Sci. 2010;67:641-53.

29. Samama B, Boehm N. Reelin immunoreactivity in lymphatics and liver during development and adult life. Anat Rec Part A. 2005;285A:595-9.

30. Lutter S, Xie S, Tatin F, Makinen T. Smooth muscle-endothelial cell communication activates reelin signaling and regulates lymphatic vessel formation. J Cell Biol. 2014;197:837-49.

31. Derer P, Derer M, Goffinet A. Axonal secretion of reelin by Cajal-Retzius cells: evidence form comparison of normal and Reln ${ }^{\text {Orl }}$ mutant mice. J Comp Neurol. 2001:440:136-43.

32. Pappas GD, Kriho V, Pesold C. Reelin in the extracellular matrix and dendritic spines of the cortex and hippocampus: a comparison between wild type and heterozygous reeler mice by immunoelectron microscopy. J Neurocytol. 2001;30:413-25.

33. Pappas GD, Kriho V, Liu WS, Tremolizzo L, Lugli G, Larson J. Immunocytochemical localization of reelin in the olfactory bulb of the heterozygous reeler mouse: an animal model for schizophrenia. Neurol Res. 2003;25:819-30.

34. Martinez-Cerdeño V, Galazo MJ, Cavada C, Clasca F. Reelin immunoreactivity in the adult primate brain: Intracellular localization in projecting and local circuit neurons of the cerebral cortex, hippocampus and subcortical regions. Cereb Cortex. 2002;12:1298-311.

35. Roberts RC, Xu L, Roche JK, Kirkpatrick B. Ultrastructural localization of reelin in the cortex in post-mortem human brain. J Comp Neurol. 2006;482:294-308.

36. Inoue K. A new approach to the quantitative analysis of the vascular architecture and its application to the cerebral cortex of the reeler mouse. Hokkaido Igaku Zasshi. 1990;65:493-509.

37. Riddell DR, Sun X-M, Stannard AK, Soutar AK, Owen JS. Localization of apolipoprotein $\mathrm{E}$ receptor 2 to caveolae in the plasma membrane. J Lipid Res. 2001;42:998-1002.

38. Cuitino L, Matute R, Retamal C, Bu G, Inestrosa NC, Marzolo MP. ApoER2 is endocytosed by a clathrin-mediated process involving the adaptor protein Dab2 independent of its rafts' association. Traffic. 2005;6:820-38.
39. Mayer H, Duit S, Hauser C, Schneider WJ, Nimpf J. Reconstitution of the reelin signaling pathway in fibroblasts demonstrates that Dab1 phosphorylation is independent of receptor localization in lipid rafts. Mol Cell Biol. 2006;26:19-27.

40. Minami SS, Hoe H-S, Rebeck GW. Fyn kinase regulates the association between amyloid precursor protein and Dab1 by promoting their localization to detergent-resistant membranes. J Neurochem. 2011;118:879-90.

41. Strasser V, Fasching D, Hauser C, Mayer H, Bock HH, Hiesberger T, et al. Receptor clustering is involved in reelin signaling. Mol Cell Biol. 2004; $24: 1378-86$

42. Divekar SD, Burrell TC, Lee JE, Weeber EJ, Rebeck GW. Ligand-induced homotypic and heterotypic clustering of apolipoprotein E receptor 2. J Biol Chem. 2014;289:15894-903.

43. Duit S, Mayer H, Blake SM, Schneider WJ, Nimpf J. Differential functions of ApoER2 and very low density lipoprotein receptor in reelin signaling depend on differential sorting of the receptors. J Biol Chem. 2010;285:4896-908.

44. Rivera-Baltanas T, Romay-Tallon R, Dopeso-Reyes IG, Caruncho HJ. Serotonin transporter clustering in blood lymphcoytes of reeler mice. Cardiovasc Psychiatry Neurol. 2010;2010:396282.

45. Dong E, Caruncho H, Liu WS, Smalheiser NR, Grayson DR, Costa E, et al. A reelin-integrin receptor interaction regulates Arc mRNA translation in synaptoneurosomes. Proc Natl Acad Sci USA. 2003;100:5479-84.

46. Caruncho HJ, Dopeso-Reyes IG, Loza MI, Rodriguez MA. GABA, reelin, and the neurodevelopmental hypothesis of schizophrenia. Crit Rev Neurobiol. 2004; 16:25-32.

47. Fatemi SH, Earle JA, McMenomy T. Reduction in reelin immunoreactivity in hippocampus of subjects with schizophrenia, bipolar disorder and major depression. Mol Psychiatry. 2000;5:654-63.

48. Fatemi SH, Kroll JL, Stary JM. Altered levels of reelin and its isoforms in schizophrenia and mood disorders. Neuroreport. 2001;12:3209-15.

49. Rivera-Baltanas T, Olivares JM, Calado-Otero M, Kalynchuk LE, Martinez-Villamarin JR, Caruncho HJ. Serotonin transporter clustering in blood lymphocytes as a putative biomarker of therapeutic efficacy in major depressive disorder. J Affect Disord. 2012;137:46-55.

50. Rivera-Baltanas T, Olivares JM, Martinez-Villamarin JR, Fenton EY, Kalynchuk LE, Caruncho $\mathrm{HJ}$. Serotonin 2A receptor clustering in peripheral lymphocytes is altered in major depression and may be a biomarker of therapeutic efficacy. J Affect Disord. 2014;163:47-55.

51. Teixeira CM, Martin ED, Sahun I, Masachs N, Pujadas L, Corvelo A, et al. Overexpression of reelin prevents the manifestation of behavioral phenotypes related to schizophrenia and bipolar disorder. Neuropsychopharmacol. 2011;36:2395-405.

52. Perez-Costas E, Gandy JC, Melendez-Ferro M, Roberts RC, Bijur GN. Light and electron microscopy study of glycogen synthase kinase-3 $\beta$ in the mouse brain. PLoS ONE. 2010; 5(1): e8911. doi:10.1371/journal.pone.0008911

\section{Submit your next manuscript to BioMed Central and take full advantage of:}

- Convenient online submission

- Thorough peer review

- No space constraints or color figure charges

- Immediate publication on acceptance

- Inclusion in PubMed, CAS, Scopus and Google Scholar

- Research which is freely available for redistribution 